\title{
Improvements in brain tumor surgery: the modern history of awake craniotomies
}

\author{
Ketan R. Bulsara, M.D., Joel Johnson, M.D., and Alan T. Villavicencio, M.D. \\ Division of Neurosurgery and Department of Anesthesiology, University of Missouri-Columbia, \\ Missouri; and Boulder Neurosurgical Associates, Boulder, Colorado
}

KEY WORDS - brain tumor - awake craniotomy • eloquent cortex • glioma

Early archaeological records indicate that awake craniotomies in the form of trephination were successfully practiced long before the advent of general anesthesia. Skulls unearthed in Peru show complete healing in 55\% of 214 patients. The possibility has been advanced that coca leaves may have allowed for trephination after cocaine-induced local anesthesia.

In many ways, the modern era of awake craniotomies began more than 50 years ago when Wilder Penfield and André Pasquet published their landmark paper on the surgical and anesthetic aspects of surgery after administration of local and intermittent sedation and analgesia. ${ }^{19}$ Many of the concepts they outlined remain relevant today. The ability to perform awake craniotomies has become a part of the armamentarium of many neurosurgeons, with significant applications in neuro-oncology. An experienced surgical and anesthetic team is essential to performing these craniotomies. The fundamental concepts of cerebral localization and improved anesthetic techniques remain relevant.

\section{Cerebral Localization}

Modern understanding of cerebral localization arises from the meticulous documentation of observations in patients. As Greenblatt ${ }^{9}$ relates, two prominent figures in the 19th century who laid the foundations of the detailed neurological examination and subsequently cerebral localization were Jean-Martin Charcot and John Hughlings Jackson. According to Greenblatt, Charcot widely applied the basic tenets of "making direct empirical correlations between clinical findings on physical examination and pathological findings" that he had learned from his predecessors. This systematic approach to neurological disorders, coupled with the increased use of microscopy, allowed for improved understanding of pathophysiological changes asso- ciated with clinical findings. Charcot's early investigative efforts led to the concept of "system diseases." As the fields of functional neuroanatomy and physiology matured, so would clinical neurology.

In 1861, Pierre Paul Broca was confronted by a patient who could understand language but could not speak. An autopsy in this patient revealed a lesion in the posterior region of the frontal lobe, an area now called the Broca area. Broca's keen observations led him to identify eight patients with similar lesions by 1864 . Based on this he declared "Nous parlons avec "hemisphere gauche'!" ("We speak with our 'left hemisphere'!" [quoted in Kandel, et al..$^{10}$ ).

At approximately the same time, John Hughlings Jackson was meticulously recording his clinical and pathological findings in patients who had suffered stroke or seizure. ${ }^{9}$ He had seen 500 patients with hemiplegia by 1865 , and he was intrigued by the apparent sparing of some muscle function in these individuals. Early in his career, Jackson believed that all sensorimotor function was subcortical. In September 1865, he reported the autopsy results in a patient with aphasia and right hemiplegia. It is here that he begins to speculate on some cortical sensorimotor function. According to Greenblatt, ${ }^{8}$ Jackson's "basic contribution to the history of cerebral localization was his extension of the sensory-motor psychophysiology to the cerebral cortices."

The work of pioneers such as Broca and Jackson prompted a search for areas of cerebral localization. In 1870, Gustav Fritsch and Eduard Hitzig elicited characteristic movements in dogs by stimulating certain areas of the animals' brain. These men's work had two significant implications: 1) that individual movements are represented in small, discrete regions of the cortex; and 2) that limb movement could be produced by stimulating the contralateral precentral gyrus. In 1874, Roberts Bartholow ${ }^{3}$ confirmed these 
findings in an unfortunate patient whose brain surface had been exposed by an ulcer. Electrical stimulation of the brain produced muscular contractions and paresthesias in the patient's contralateral arm and leg. ${ }^{12}$

The momentum for advancing the concept of cerebral localization was slowly growing. In 1876, Carl Wernicke published a landmark paper called "The Symptom Complex of Aphasia: A Psychological Study on an Anatomical Basis." In this paper he presented a group of patients who could speak but could not comprehend. The cortical lesion in these patients was located in the posterior part of the temporal lobe, at its junction with the parietal and occipital lobes. This report advanced the concept that different components of a single behavior could be processed in different regions of the brain.

These findings laid the groundwork for Wilder Penfield's investigations. In 1928, Penfield spent 6 months with Otfrid Foerster studying the pathogenesis and surgical management of epilepsy. ${ }^{4,5,14}$ It is here that he became familiar with Foerster's method of cortical stimulation in the excision of brain scars caused by gunshot wounds. When Penfield returned to Montreal, he initially adopted this method to reproduce features of the patient's seizures intraoperatively after application of local anesthesia. Penfield's initial application of the technique was to epilepsy surgery. Galvanic current was used to outline motor and sensory areas, and a faradic coil was used to reproduce features of a seizure. He used a thyratron stimulator with unilateral or bipolar electrodes consisting of a platinum wire in a glass holder. ${ }^{13,16}$ Not only was Penfield an astute clinician/surgeon, he also meticulously and methodically documented his intraoperative findings. ${ }^{15,16,18,20,22}$

The map for cerebral localization that Penfield proposed remains the one used today. In 1937, Penfield and Boldrey established cortical maps for motor and sensory responses, which are now depicted by the sensory and motor homunculus. ${ }^{15}$ In 1941, Penfield and Erickson noted that stimulation of temporal cortex in patients occasionally excited recall of vivid memories. ${ }^{16,17}$ The observations detailed by Penfield in association with Rasmussen and Roberts form a unique source of insight into the mechanism of speech. ${ }^{20,21}$

\section{Anesthetic Techniques}

According to Wicker, ${ }^{25}$ Koller introduced the use of cocaine as a local anesthetic in 1884. The short-acting nature of this drug and its potent analgesic ability had significant appeal. This appeal served as an impetus for Alfred Einhorn, who synthesized procaine hydrochloride in 1899. By 1901 the widespread use of local anesthetic drugs led Harvey Cushing to introduce the term "regional anesthesia."

With the increased use of local anesthetic agents, there was increasing demand for intermediate- and long-acting drugs. Wicker ${ }^{25}$ recounts how Lofgren and Lundqvist introduced lignocaine hydrochloride, an intermediate-acting agent, in 1943. This was followed by the synthesis of prilocaine hydrochloride in 1959, and by Ekenstam's introduction of the long-acting local anesthetic bupivacaine in 1957.

The availability of these drugs would begin to pave the way for neurosurgical advancements in the realm of awake craniotomies. After 30 years of surgical experience in refining awake craniotomies, Wilder Penfield stated that "the patient must be conscious and alert while electrical stimulation is being carried out. He must often aid the surgeon by saying what sensations he may have. He must warn quickly if the operator should produce the aura of his attack. When cortical excision is planned in the dominant hemisphere, the patient must read or talk or sometimes write while the surgeon is tentatively interfering with an area of cortex essential to speech."19 The goal of anesthetic regimens in brain surgery has been to maximize patient comfort, yet allow for awake cortical mapping. The modern age of anesthesia for awake craniotomies began with local anesthesia being administered by neurosurgeons (Table 1).

The use of only local anesthetic agents was popular because of the absence of associated intraoperative problems. With the early agents, patient comfort could not always be guaranteed. Long-acting agents, such as bupivacaine, heralded an advance that allowed longer surgical times with increased patient comfort. ${ }^{7}$ It was not until the 1960s that the use of neuroleptic techniques with fentanyl (or its ana$\operatorname{logs}$ ) and droperidol allowed for anesthesia with amnesia. ${ }^{24}$ One of these combinations, Innovar, was marketed specifically for neuroleptanesthesia. With Innovar, patients were drowsy, yet able to follow commands, and respiratory function and hemodynamic stability were maintained. The early enthusiasm for these regimens faded as the occurrence of numerous side effects became established. These included extrapyramidal and anticholinergic symptoms, dysphoria, hypotension with large doses, and a long duration of action.

In the 1990s, propofol, a hypnotic agent, was reformulated with egg lecithin and rapidly gained popularity. Its use was advantageous in awake craniotomies because of its hypnotic properties during surgery, and its rapid redistribution resulted in quick return to consciousness during awake intraoperative monitoring. ${ }^{23}$ Propofol used as a sole agent lacked analgesic properties. Therefore, the synthetic opioids fentanyl, alfentanil, and sufentanil were used in conjunction with propofol to provide a smooth anesthetic experience with analgesia. ${ }^{6}$

The introduction of the ultrashort-acting opioid remifentanil led to the establishment of today's anesthetic regimen of choice for awake craniotomies. The modern regimen of propofol and remifentanil now allows the anesthesiologist to control closely a patient's level of analgesia and sedation. A remifentanil infusion of between 0.05 and $0.10 \mu \mathrm{g} /$ $\mathrm{kg} / \mathrm{min}$ provides for good perioperative analgesia when used in conjunction with local anesthetic agents administered by the surgeon. Varying the propofol infusion between 0 and 50 to $75 \mu \mathrm{g} / \mathrm{kg} / \mathrm{min}$ can keep a patient sedat-

\section{TABLE 1}

History of anesthesia use in awake craniotomy

\begin{tabular}{ll}
\hline \hline Surgeon \& Year & \multicolumn{1}{c}{ Anesthesia Method } \\
\hline Horsley, 1886 & local \\
Davidoff, 1934 & local w/ sedation \\
Penfield, 1937 & local, sedation after testing \\
Pasquet, 1953 & local w/ terminal general \\
De Castro, 1959 & neuroleptanesthesia \\
Ingram, 1959 & intermittent general \\
Gilbert, 1966 & Innovar \\
Silbergeld, 1992 & propofol sedation for craniotomy \& after testing \\
\hline
\end{tabular}


ed. The advantage of this combination regimen is that it ensures patient comfort, yet allows for rapid return to consciousness intraoperatively for awake cortical mapping.

The future development of anesthetic agents for awake craniotomies continues to hold promise. Recently the Food and Drug Administration approved dexmedetomidine, an alpha-2 agonist, as a sedative for use in the intensive care unit. This drug provides a moderate amount of sedation with some centrally derived analgesia. It has a decreased potential for respiratory depression. Patients receiving this drug may be quite somnolent but respond purposefully when aroused. Dexmedetomidine has been used successfully as the sole agent for awake craniotomies. ${ }^{11}$ In addition, it has been shown to be useful in the pediatric population. ${ }^{2}$

\section{CONCLUSIONS}

"Two things we must learn from history.... One is that we are not in ourselves superior to our fathers and that we are shamefully and monstrously inferior to them if we do not advance beyond them." The principles of awake craniotomies were established more than 50 years ago. As our understanding of the physiology of cerebral localization and anesthetic regimens continues to improve, awake craniotomies will continue to provide critical insights into the complexities of brain function.

\section{Acknowledgments}

We thank Nita K. Bulsara, R.P.H., Amanda Forshee, and Laura Kays for their editorial assistance with the manuscript. Drs. Bulsara and Villavicencio also thank Dr. Allan Friedman, chief of the Division of Neurosurgery at Duke University Medical Center, for teaching them the principles of awake craniotomies.

\section{References}

1. Al-Mefty O: Operative Atlas of Meningiomas. Philadelphia: Lippincott-Raven Publishers, 1997

2. Ard J, Doyle W, Bekker A: Awake craniotomy with dexmedetomidine in pediatric patients. J Neurosurg Anesthesiol 15: 263-266, 2003

3. Bartholow R: Experimental investigations into the functions of the human brain. Am J Med Sci 7:305-313, 1874

4. Eccles JF, Feindel W: Wilder Graves Penfield (1891-1976). Biograph Mem Fell Royal Soc 24:473-513, 1978

5. Feindel W: Wilder Penfield: his legacy to neurology. To praise an absent friend. Can Med Assoc J 116:1365-1367, 1977

6. Gignac E, Manninen PH, Gelb AW: Comparison of fentanyl, sufentanil and alfentanil during awake craniotomy for epilepsy. Can J Anaesth 40:421-424, 1993
7. Girvin JP: Neurosurgical considerations and general methods for craniotomy under local anesthesia. Int Anesthiol Clin 24: 89-114, 1986

8. Greenblatt SH: Cerebrospinal fluid creatine phosphokinase in acute subarachnoid hemorrhage. J Neurosurg 44:50-54, 1976

9. Greenblatt SH: The development of modern neurological thinking in the 1860s. Perspect Biol Med 35:129-139, 1991

10. Kandel ER, Schwartz JH, Jessell TM: Principles of Neural Science, ed 3. Norwalk, CT: Appleton \& Lange, 1991

11. Mack PF, Perrine K, Kobylarz E, et al: Dexmedetomidine and neurocognitive testing in awake craniotomy. J Neurosurg Anesthesiol 16:20-25, 2004

12. Morgan JP: The first reported case of electrical stimulation of the human brain. J Hist Med Allied Sci 37:51-64, 1982

13. Penfield W: Epilepsy and surgical therapy. Arch Neurol Psychiatry 36:449-484, 1936

14. Penfield W: No Man Alone: A Neurosurgeon's Life. Boston: Little, Brown, 1977

15. Penfield W, Boldrey E: Somatic motor and sensory representation in the cerebral cortex of man as studied by electrical stimulation. Brain 60:389-443, 1937

16. Penfield W, Erickson TC: Epilepsy and Cerebral Localization: A Study of the Mechanism, Treatment, and Prevention of Epileptic Seizures. Springfield, IL: Charles C Thomas, 1941

17. Penfield W, Flanigin H: Surgical therapy of temporal lobe seizures. Arch Neurol Psychiatry 64:490-500, 1950

18. Penfield W, Jasper H: Epilepsy and the Functional Anatomy of the Human Brain. Boston: Little, Brown, 1954

19. Penfield W, Pasquet A: Combined regional and general anesthesia for craniotomy and cortical exploration. Part 1 . Neurosurgical considerations. Int Anesthiol Clin 24:1-20, 1986

20. Penfield W, Rasmussen T: The Cerebral Cortex of Man. New York: Macmillan, 1950

21. Penfield W, Roberts L: Speech and brain mechanisms. Princeton: Princeton University Press, 1959

22. Rasmussen T: Surgical treatment of complex partial seizures: results, lessons, and problems. Epilepsia 24 (Suppl 1): S65-S76, 1983

23. Silbergeld DL, Mueller WM, Colley PS, et al: Use of propofol (Diprivan) for awake craniotomies: technical note. Surg Neurol 38:271-272, 1992

24. Welling EC, Donegan J: Neuroleptanalgesia using alfentanil for awake craniotomy. Anesth Analg 68:57-60, 1989

25. Wicker P: Local anaesthesia in the operating theatre. Nurs Times 90:34-35, 1994

Manuscript received February 7, 2005.

Accepted in final form March 29, 2005.

Address reprint requests to: Ketan R. Bulsara, M.D., One Hospital Drive, N502, University of Missouri-Columbia, Columbia, Missouri 65212. email: bulsarak@ health.missouri.edu. 